EPJ Web of Conferences 59, 11005 (2013)

DOI: $10.1051 /$ epjconf/20135911005

(C) Owned by the authors, published by EDP Sciences, 2013

\title{
Studies of a self-cooled lead lithium blanket for HiPER reactor
}

\author{
R. Juárez ${ }^{1,2}$, J. Sanz ${ }^{1,2}$, C. Sánchez ${ }^{2}$, C. Zanzi ${ }^{3}$, J. Hernández ${ }^{3}$ \\ and J.M. Perlado ${ }^{1}$ \\ ${ }^{1}$ Instituto de Fusión Nuclear, UPMIUNED, C/Jose Gutiérrez Abascal 2, Madrid, Spain \\ ${ }^{2}$ Dept. de Ingeniería Energética, ETSII, UNED, Cl Juan del Rosal 12, Madrid, Spain \\ ${ }^{3}$ Dept. de Ingeniería Mecánica, ETSII, UNED, Cl Juan del Rosal 12, Madrid, Spain
}

\begin{abstract}
Within the frame of the HiPER reactor, we propose and study a Self Cooled Lead Lithium blanket with two different cooling arrangements of the system First Wall - Blanket for the HiPER reactor: Integrated First Wall Blanket and Separated First Wall Blanket. We compare the two arrangements in terms of power cycle efficiency, operation flexibility in out-off-normal situations and proper cooling and acceptable corrosion. The Separated First Wall Blanket arrangement is superior in all of them, and it is selected as the advantageous proposal for the HiPER reactor blanket. However, it still has to be improved from the standpoint of proper cooling and corrosion rates.
\end{abstract}

\section{INTRODUCTION}

The HiPER reactor is conceived to be a $1500 \mathrm{MWth}$ reactor, based on direct drive shock ignition and dry wall technologies [1]. From this starting point, it is necessary to propose and optimize a tritium breeding blanket for the reactor. In this paper we propose and study a self-cooled lead lithium (SCLL) blanket with EUROFER structure. There is the possibility of decoupling the First Wall and the Blanket cooling leading to two different First Wall-blanket arrangements: Integrated First Wall Blanket (IFWB) and Separated First Wall Blanket (SFWB). For both of them, we have assessed and compared some critical performances of the reactor: Tritium Breeding Ratio (TBR), power cycle efficiency, response against cooling accidents, proper blanket cooling and corrosion rates inside the blanket.

\section{SELF-COOLED LEAD LITHIUM BLANKET}

We propose as starting design Self Cooled Lead Lithium with EUROFER structure. This design proposal is aimed to be modified as different studies answer open questions. It is conceived to be arranged as shown in Fig. 1. It is divided in two different hemispheres. Every hemisphere is divided into 8 modules. All the EUROFER sheets are $1 \mathrm{~cm}$ thick, unless other thickness is specifically mentioned. Every module has a thin inlet channel and a thick outlet channel. The inner channel is comprised between radius $6.51 \mathrm{~m}$ and $6.59 \mathrm{~m}(8 \mathrm{~cm}$ thickness channel). The outlet channel is comprised between radius $6.81 \mathrm{~m}$ and $7.47 \mathrm{~m}$ ( $66 \mathrm{~cm}$ thickness channel). The inlet temperature is $350{ }^{\circ} \mathrm{C}$ and the desired outlet temperature is $450{ }^{\circ} \mathrm{C}$.

A neutronic analysis of this blanket proposal has been performed regarding Tritium Breeding Ratio (TBR) and blanket energy gain $\left(\eta_{\mathrm{B}}\right)$. The TBR results to be as high as 1.38 for the reference design. Then, we have computed the TBR as function of the First Wall steel substrate thickness. The maximum FW substrate thickness has been found to be as $5.5 \mathrm{~cm}$ to obtain a TBR $>1.15$ [2]. This result opens the possibility of decoupling the cooling of the blanket and the First Wall. The $\eta_{B}$ is 1.18 .

This is an Open Access article distributed under the terms of the Creative Commons Attribution License 2.0, which permits unrestricted use, distribution, and reproduction in any medium, provided the original work is properly cited. 

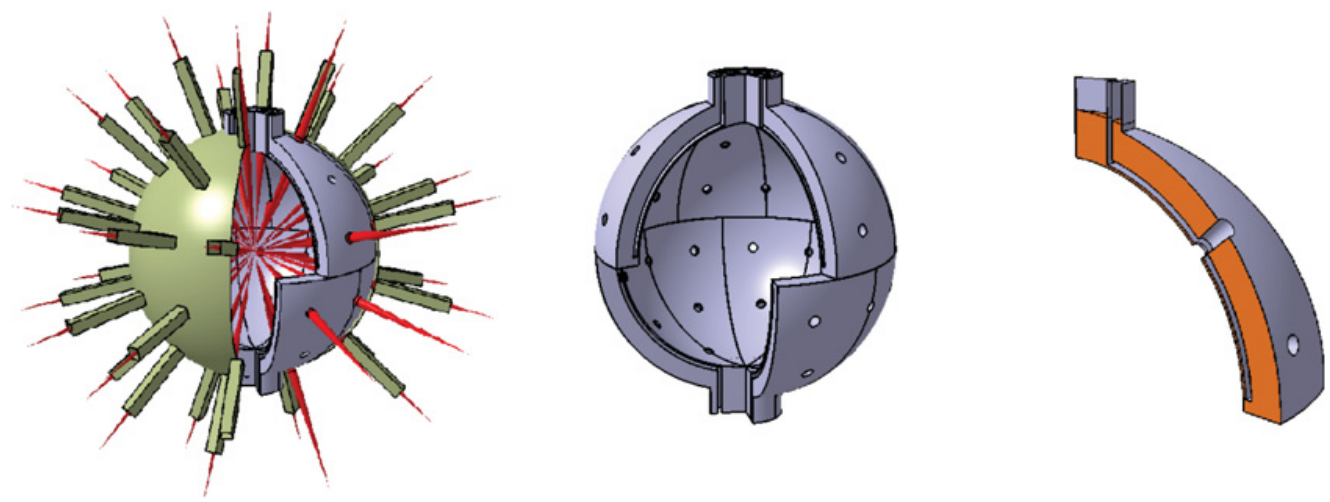

Figure 1. Blanket and vacuum chamber of HiPER reactor.

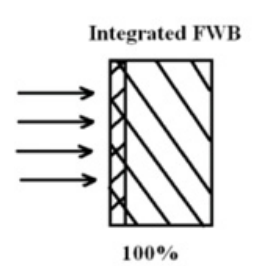

$\mathbb{N}_{\text {Neutrons }} \theta_{\text {Xrays }}^{\text {Ions }}$

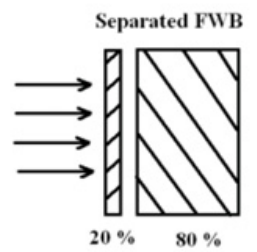

(including the blanket gain)

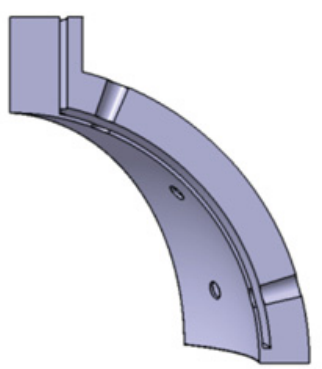

Integrated First Wall Blanket arrangement IFWB

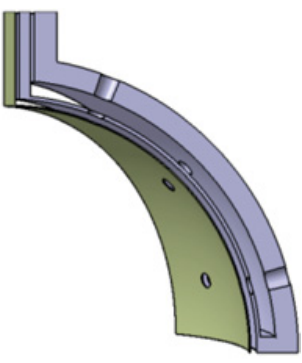

Separated First Wall Blanket arrangement SFWB

Figure 2. Neutron, ion and X-rays energy deposition in IFWB and SFWB.

The neutrons generated in the ignition will deposit their energy (75\% of the generated energy, $\left.1125 \times \eta_{\mathrm{B}}=1327.5 \mathrm{MW}\right)$ in the Lead Lithium $(\mathrm{LiPb})$ and the structure of the blanket. The ions and $\mathrm{X}$-rays produced in the ignitions will deposit their energy (25\% of the generated energy, $375 \mathrm{MW}$ ) directly into the First Wall, as the HiPER reactor is a dry wall concept. In the first approach to the problem, the energy deposited in the FW is transferred to the LiPb and it is evacuated together with the neutron energy deposition. This option is called the Integrated First Wall - Blanket arrangement. However, given the neutronic performance of the starting design, it is possible to decouple the FW and blanket cooling. Both First Wall - Blanket options are shown in Figure 2.

There are different potential improvements in the blanket performance that motivate the decoupling of the FW and blanket cooling. First of all, the ion and X-ray energy will raise the LiPb temperature/velocity with no extra TBR advantage. The SCLL is characterized by a fast flowing LiPb, and corrosion can be a threat. Then, by reducing the $\mathrm{LiPb}$ temperature/velocity the corrosion rates can be partially mitigated. The FW could be built of ODS-EUROFER, allowing a maximum temperature of $650{ }^{\circ} \mathrm{C}$ for its cooling circuit. In addition, the separated First Wall could be cooled with a branch of Helium coming from the secondary circuit if Helium is used as working fluid for the power cycle conversion, as it is in this study. This Helium re-heating, from $450{ }^{\circ} \mathrm{C}$ to $650^{\circ} \mathrm{C}$ can increase the power cycle efficiency. And the introduction of a second cooling/heating independent circuit inside the Vacuum Vessel could be used to add extra operation margins in out-off-normal situations. 


\section{IFSA 2011}

IFWB

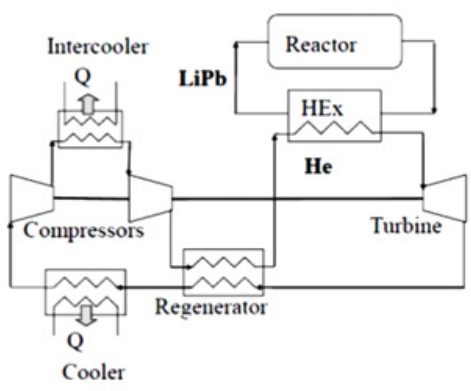

SFWB

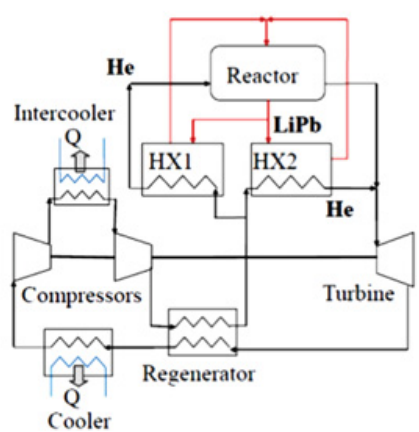

Figure 3. Helium Brayton power cycle for the SCLL blanket of HiPER reactor.

\section{HELIUM BRAYTON POWER CYCLE}

As a first approach to the power conversion issue, we have decided to study a Helium Brayton [3, 4] Power cycle for both IFWB and SFWB. They are shown in Figure 3.

A regenerative and intercooling helium Brayton cycle is proposed for both configurations. In the SFWB configuration, the proposed power cycle integrates the two energy sources. The efficiency of the power cycle for the IFWB is $37.5 \%$, while that for the SFWB is $38.5 \%$.

\section{LOSS OF ACTIVE COOLING}

The study of the consequences of a severe accident in HiPER reactor exceeds the scope of this paper. Instead of severe accidents, we have first focused on out-off-normal situations, where the SCLL blankets are limited for having only one single heating/cooling circuit. In these situations, such as the loss of active cooling, there are two main threats identified: LiPb solidification inside the blanket and the structure mechanical degradation. The specific threat will depend on the previous irradiation to the loss of coolant accident, given that residual heat can be very important.

We have developed a simple computational model for the heat transfer studies of the SCLL blanket for HiPER reactor, and compared the operation flexibility in these situations for both arrangements: IFWB and SFWB. The IFWB is very limited. In the absence of residual heat in 40 hours the LiPb becomes solid inside the blanket. This is the maximum time to evacuate it from the blanket. But, after 5 years of irradiation, the residual heat is such that in 10 hours the structure temperature has overcome the limit of $550{ }^{\circ} \mathrm{C}$. Above this temperature, the creep rupture can represent a threat for the EUROFER structure. In the case of the SFWB, the FW independent cooling circuit could be adapted to operate as auxiliary heating/cooling circuit if it were in thermal contact with the blanket. Our calculations show that some MWs of heating/cooling capacity would be enough for this circuit to avoid both risks: solidification of $\mathrm{LiPb}$ inside the blanket and structural properties deterioration. Some MWs for auxiliary operation should not represent a design threat for a circuit which in normal operation will extract around 450 MWs from the FW.

\section{ACTIVE COOLING AND CORROSION}

The proper cooling of the blanket can be synthesized in the three following requirements:

1. Average outlet temperature of $\mathbf{L i P b}$ of $450{ }^{\circ} \mathbf{C}$, a compromise between power cycle conversion and corrosion rates in the plant [5]. 
Table 1. Cooling parameters of the IFWB and the SFWB.

\begin{tabular}{|l|c|c|c|c|c|}
\hline & $\begin{array}{c}\text { Power in the } \\
\text { LiPb }(\mathbf{M W})\end{array}$ & $\begin{array}{c}\text { LiPb mass flow } \\
(\mathbf{k g} / \mathbf{s})\end{array}$ & $\begin{array}{c}\text { Max. corrosion } \\
\text { rate }(\boldsymbol{\mu m} / \mathbf{y r})\end{array}$ & $\mathbf{T}_{\max }\left({ }^{\circ} \mathbf{C}\right)$ & $\mathbf{T}_{\text {out }}\left({ }^{\circ} \mathbf{C}\right)$ \\
\hline IFWB & 1702.5 & 12100 & 3300 & 539.5 & 395.5 \\
\hline SFWB & 1327.5 & 9700 & 2700 & 515 & 395.5 \\
\hline
\end{tabular}

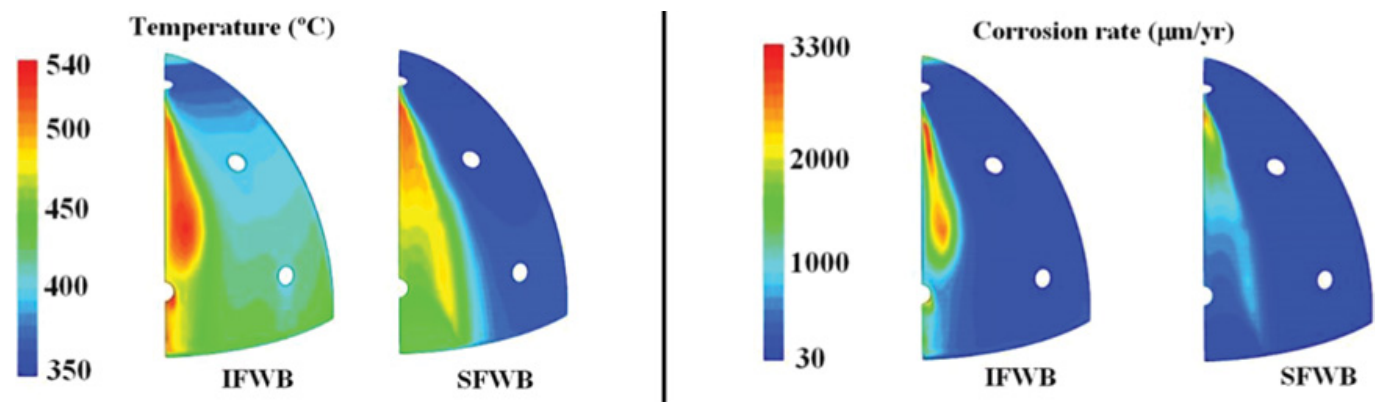

Figure 4. Temperature and corrosion rates maps of the IFWB and the SFWB.

2. Maximum local temperature of $\mathrm{LiPb}$ inside the blanket of $550{ }^{\circ} \mathrm{C}$, to fulfil the EUROFER criterion on creep rupture behaviour [6].

3. Maximum corrosion rate inside the blanket of $200 \mu \mathrm{m} / \mathbf{y r}$. After 5 years of lifetime of the blanket, the total corrosion would be $1 \mathrm{~mm}, 10 \%$ of the structure thickness [5].

We have computed the temperature and corrosion maps [7] for the IFWB and SFWB arrangements, with the cooling parameters shown in Table 1. The mass flow rate has been fixed in order to keep the temperature below the local upper limit of $550{ }^{\circ} \mathrm{C}$ in both cases.

As expected, an improvement in the fluid-dynamics performance (max. local temperature and corrosion rates) is found in the case of SFWB compared to the IFWB (see Table 1). However, there is still a need for improvement. As shown in Figure 4, there is a large LiPb recirculation area in the blanket inlet for both the IFWB and SFWB. It is responsible for the bad performance of both arrangements in terms of low outlet temperature and high corrosion rates. Further modifications of the blanket design will take into account this fact to improve the cooling.

\section{CONCLUSIONS}

We have proposed and studied a SCLL blanket with two different arrangements for the First Wall Blanket cooling system for the HiPER reactor: IFWB and SFWB. We have compared them in terms of power cycle efficiency, out-off-normal situations and cooling and corrosion. The SFWB is superior in all of these fields and it is chosen for further studies as the advantageous option. However the SFWB still has to be modified to improve the cooling and corrosion performance.

\section{References}

[1] M. Dunne et al., HiPER Technical Background and Conceptual Design Report (2007)

[2] L.A. El-Guebaly, S. Malang, Fusion Engineering and Design 84, 2072 (2009)

[3] T.J. Dolan, Fusion Research, Pergamon International Library III 747 (1980)

[4] R. Juárez, C. Sánchez, J. Sanz, J.M. Perlado, submitted to Fusion Engineering and Design

[5] S. Malang, A.R. Raffray, N.B. Morley, Fusion Engineering and Design 84, 2145 (2009)

[6] S.J. Zinkle, N.M. Ghoniem, Journal of Nuclear Materials 417, 2 (2011)

[7] J. Sannier, T. Dufrenoy, T. Flament, A. Terlam, Journal of Nucl. Mat. 191-194, 975 (1992) 